\title{
Henning Sirringhaus Fosters an Ideal Marriage of University Research and Entrepreneurship
}

When Henning Sirringhaus became the Hitachi Professor of Electron Device Physics at Cambridge University, he faced a dilemma. He said, "I don't really get very excited by basic science for which there is no application in sight on the horizon and where I couldn't explain to my wife and children why I'm doing that."

The solution was to combine science with commerce. Today he is the cofounder and chief scientist of Plastic Logic, a company that specializes in very thin, flat-panel displays, all while simultaneously working in academia. It has proven to be an ideal marriage of research and entrepreneurship. Sirringhaus (along with co-founder Richard Friend) has witnessed the small start-up company, Plastic Logic, grow into three home bases: Cambridge, United Kingdom; Mountain View, California in the United States; and Dresden, Germany with nearly 200 employees.

Blending science and business has proven beneficial for both arenas. Sirringhaus said, "It happens quite often when you get involved in a spin-off company, some of the development issues actually hide some very interesting scientific questions, and you find them by working with a company. And sometimes that inspires our scientific research."

Sirringhaus began his university education in his homeland of Germany. He then moved to Switzerland and eventually earned a PhD degree from ETH Zürich in semiconductor physics. Next, it was off to the United States to do post-doctoral work at Princeton before finally landing at Cambridge where he is the Hitachi Professor of Electron Device Physics. He is also head of the Microelectronics and Optoelectronics Group working on the field of charge transport in organic semiconductors and their application in fieldeffect transistors. In 2000 he co-founded

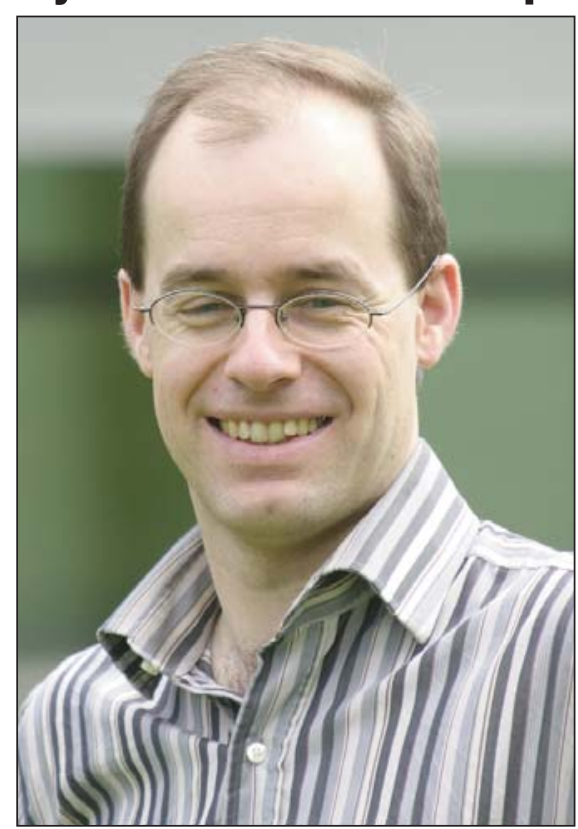

Henning Sirringhaus, co-founder of

Plastic Logic.

Plastic Logic Ltd., a technology start-up company commercializing printed organic transistor technology.

"Most young academics who see an opportunity for commercializing their science face that dilemma that you're not quite sure whether you should devote $100 \%$ of your energy on your scientific research and writing as many publications as possible, or whether you can, at least, spend part of your time on helping a young spinoff to come off the ground."

Cambridge has become a center for high-technology and Plastic Logic is just one of many start-up companies. Sirringhaus estimates that there are nearly 30,000 high-tech jobs in the area. "Not as big as Silicon Valley," he said; "but there is a certain entrepreneurial culture."

But why Cambridge?

"It's a combination of many factors," according to Sirringhaus; "Never underestimate the infrastructure." He credits the University for encouraging such partnerships between technology and business. "The University runs entrepreneur courses where undergraduate and graduate students can attend and be introduced to some of the things they need to know-how to raise money, how to put together a business plan, intellectual property, legal issues related to starting a company," he said. Sirringhaus feels it is crucial for people to have that background knowledge that they can then apply when an opportunity arises.

Another contributing factor is that the United Kingdom supplies government funding for these commercial projects. "The EPSRC, the Engineering and Physical Science Research Council, has a number of different programs that have started to improve the exploitation of science. They are increasingly concerned about not letting opportunities pass; and when there is an invention that can be exploited, that there is an effective path to do that."

It was the EPSRC that was responsible for providing the funding for Plastic Logic and its invention.

The company had been pursuing the application of electronic reading devices that would mimic the properties of paper. Sirringhaus said, "You read your newspapers and books on paper because it's comfortable. And it's much less comfortable to read it on an electronic device." The display on phones is small, and it's not possible to read attachments. When using a laptop on a train or in bed, there is always the danger of breakage. So Plastic Logic has developed an active matrix display fabrica-

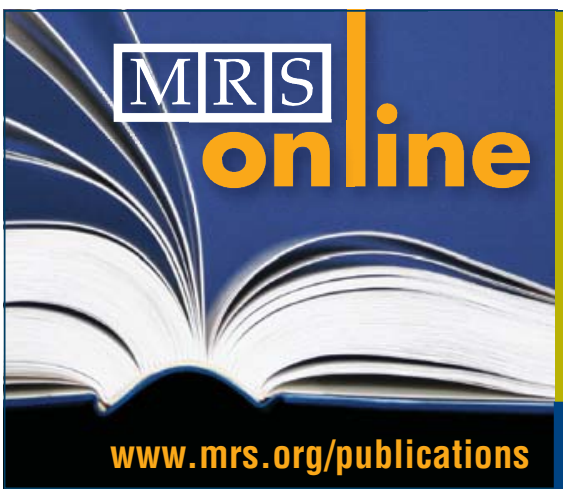

PROCEEDINGS LIBRARY

Recommano

TO YOUR LIBRARY

TODAY!

Expanded online resources for the materials community. Now available to libraries and institutions!

12-month unlimited access to over 25,000 papers- proceedings volumes published from our 1998 MRS Fall Meeting to the present, with more current and back issues added daily.

For more information, contact:

Anita B. Miller, Materials Research Society, 506 Keystone Drive, Warrendale, PA 15086

Tel: 724-779-3004, X 551; Fax: 724-779-8313; amiller@mrs.org 


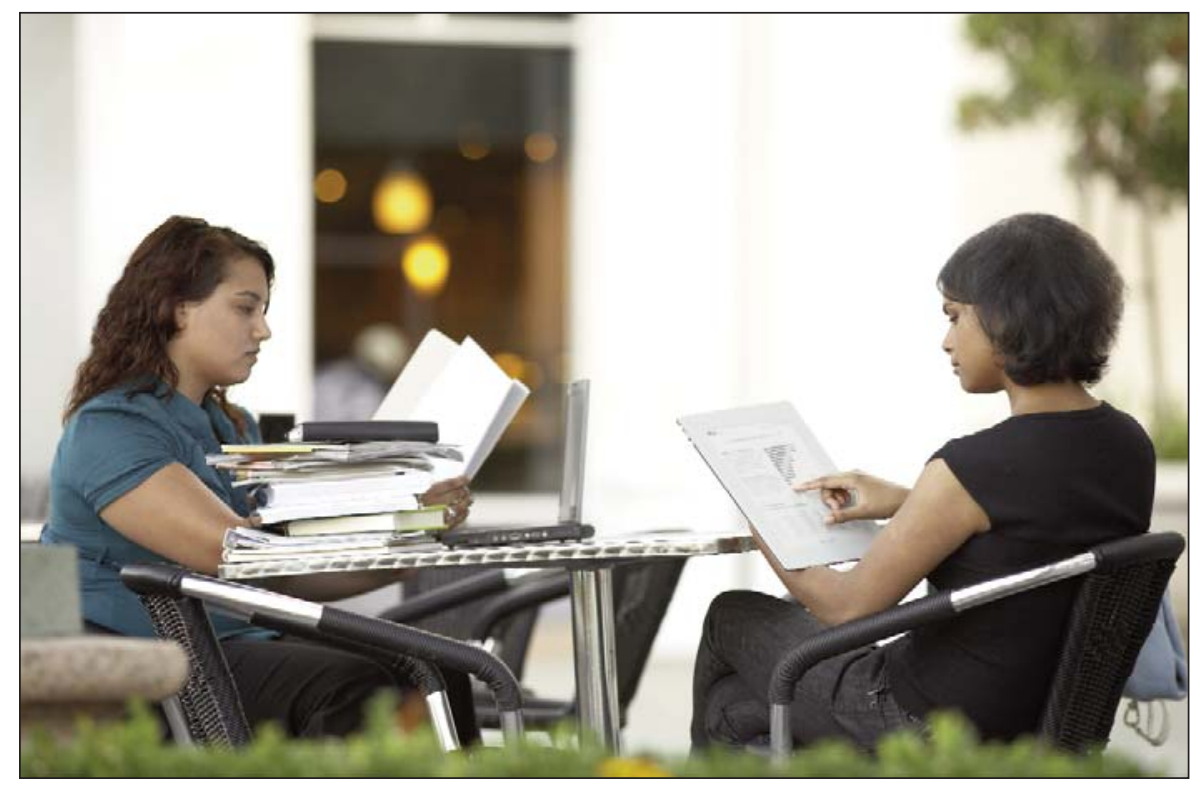

Plastic Logic Reader-Before and After.

tion process based on organic semiconductors that allows them to make millions of transistors on a PET [polyethylene terephthalate] substrate and then use that to drive electronic paper or an electrophoretic display. This eliminates a conventional display on highly breakable glass. According to Sirringhaus, a display built on PET is unbreakable. "You can drop it and you can push it. It just doesn't break."

A factory to build the PET displays opened September 17, 2008 in Dresden. It will create a million displays a year. These flexible displays will then be integrated into an electronic reader, which is developed in California.

What advice would Sirringhaus give individuals interested in following in his footsteps? "It's important to look for real opportunities," he said. But he cautioned, "If you come to do a $\mathrm{PhD}$ in order to spin off a company, that doesn't really work. I think it might be more likely that you stumble across an opportunity when you are doing really high-quality fundamental science and trying to solve really hard problems than if you're being too focused on actually starting a company and maybe taking shortcuts."

To those committed, he adds, "Of course it is important to think about what the market needs. What are the real problems? What do people need? And think about solutions to those problems."

In closing, Sirringhaus recommends, "However, it is equally important to strive for scientific excellence. Just do good science and look out for opportunities."

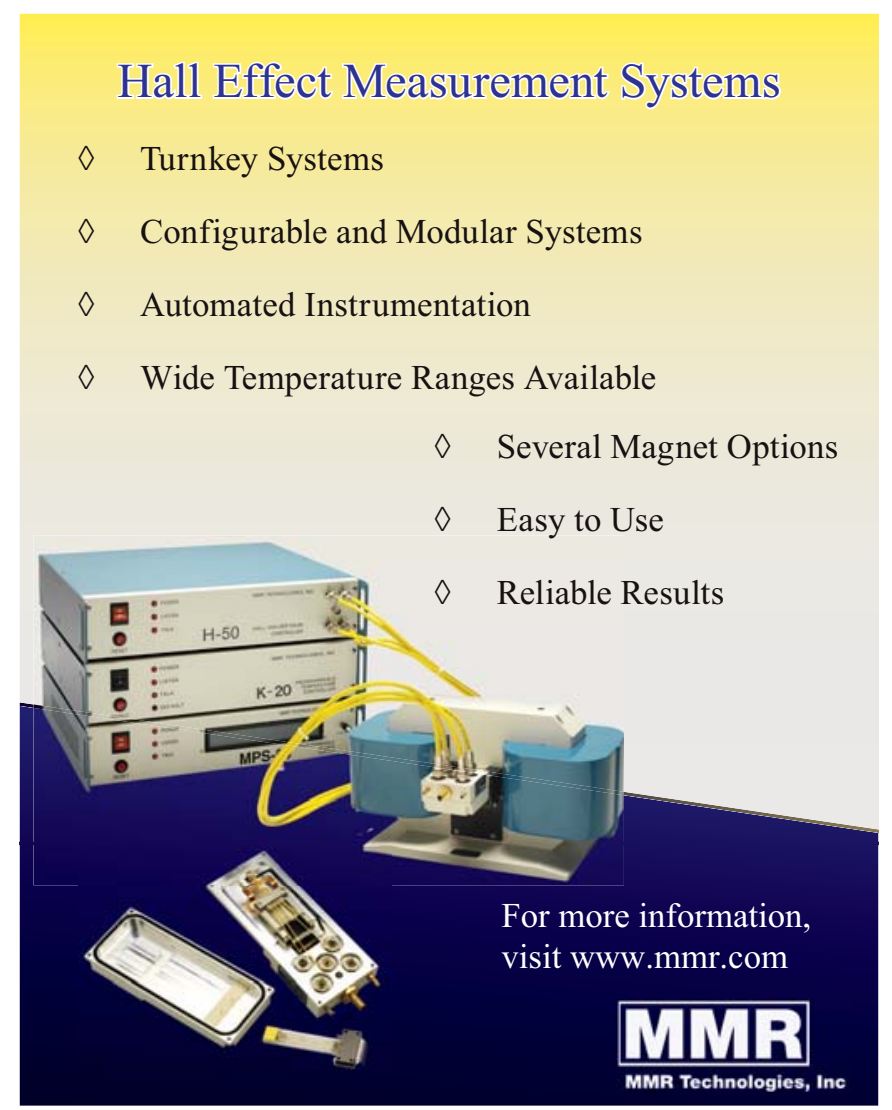

\section{$\mathrm{J} A \mathrm{~N} \mid \mathrm{S}$}

\section{UHV Micromanipulated} Probe

\section{Station}

UVH environment for electro-optical probing of wafers, chips, nanoscale devices

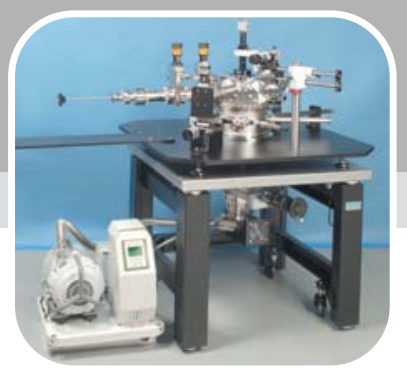

Vacuum level: $\sim 5 \times 10^{-8}$ Torr at $290 \mathrm{~K}$ and $\sim 5 \times 10^{-9}$ Torr at $5 \mathrm{~K}$

U Ultra-low vibrations ( $<2 \mathrm{~nm} / \mathrm{min}$ position drift) and wide temperature range ( $4-450 \mathrm{~K})$

- Rapid sample change via load lock with proprietary demountable cryogenic sample holder

Two to six probes, DC to $67 \mathrm{GHz}$, plus fiber optics

- Complete package includes temperature controller, zoom monoscope, integrated turbopump, vibration isolation stand

Janis Research Company
2 Jewel Drive Wilmington, MA 01887 USA
TEL +1 978 657-8750 FAX +1 978 658-0349 sales@janis.com
Visit our website at WWW.janis.com

